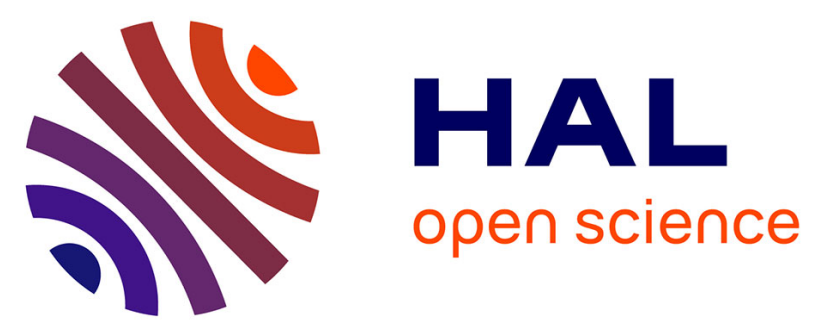

\title{
Modelling of immunosensor response: the evaluation of binding kinetics between an immobilized receptor and structurally-different genetically engineered ligands
}

Zigmas Balevicius, Julian Talbot, Linas Tamosaitis, Ieva Plikusiene, Arunas Stirke, Gitana Mikiene, Saulius Balevicius, Andrius Paulauskas, Arunas Ramanavicius

\section{To cite this version:}

Zigmas Balevicius, Julian Talbot, Linas Tamosaitis, Ieva Plikusiene, Arunas Stirke, et al.. Modelling of immunosensor response: the evaluation of binding kinetics between an immobilized receptor and structurally-different genetically engineered ligands. Sensors and Actuators B: Chemical, 2019, 297, pp.126770. 10.1016/j.snb.2019.126770 . hal-03086750

\section{HAL Id: hal-03086750 https://hal.science/hal-03086750}

Submitted on 5 Jan 2021

HAL is a multi-disciplinary open access archive for the deposit and dissemination of scientific research documents, whether they are published or not. The documents may come from teaching and research institutions in France or abroad, or from public or private research centers.
L'archive ouverte pluridisciplinaire HAL, est destinée au dépôt et à la diffusion de documents scientifiques de niveau recherche, publiés ou non, émanant des établissements d'enseignement et de recherche français ou étrangers, des laboratoires publics ou privés. 
Z. Balevicius, J. Talbot, L. Tamosaitis, I. Plikusiene, A. Stirke, G. Mickiene, S. Balevicius, A. Paulauskas, A. Ramanavicius. Modelling of immunosensor response: the evaluation of binding kinetics between an immobilized receptor and structurally-different genetically engineered ligands. Sensors and Actuators B Chemical 2019, 297, 126770. DOI:10.1016/j.snb.2019.126770

https://doi.org/10.1016/j.snb.2019.126770

Journal version is available:

https://www.sciencedirect.com/science/article/abs/pii/S0925400519309700?via\%3Dihub

\section{Modelling of immunosensor response: the evaluation of binding kinetics between an immobilized receptor and structurally-different genetically engineered ligands}

Zigmas Balevicius, ${ }^{1,2}$ Julian Talbot, ${ }^{3}$ Linas Tamosaitis, ${ }^{4}$ leva Plikusiene, ${ }^{1,4}$ Arunas Stirke, ${ }^{1}$ Gitana Mickiene, ${ }^{5}$ Saulius Balevicius, ${ }^{1}$ Andrius Paulauskas, ${ }^{1}$ Arunas

Ramanavicius, ${ }^{1,4 *}$

${ }^{1}$ Center for Physical Sciences and Technology, Semiconductor Physics Institute, Saulëtekio Ave.3, LT-10257, Vilnius, Lithuania,E-mail: zigmas.balevicius@ftmc.lt

2 Vilnius Gediminas Technical University, Naugarduko 41, LT-03227, Vilnius, Lithuania;

3 Sorbonne Université, CNRS, Laboratoire de Physique Théorique de la Matière Condensée, LPTMC, F-75005, Paris, France;

4 Vilnius University, Department of Physical Chemistry, Faculty of Chemistry and Geoscience, Universiteto 3, LT-10257, Vilnius, Lithuania;

${ }^{5}$ Life Sciences Center, Vilnius University, Vilnius, Lithuania, Saulėtekio av. 7

*E-mail of corresponding author: arunas.ramanavicius@chf.vu.It

\section{ABSTRACT}

In this research we have evaluated the binding kinetics between an immobilized receptor and several genetically engineered ligands, differing by molecular mass or by the number of binding sites available for the binding to the receptor. Genetically engineered protein (GCSF-Receptor), which contains some antibody parts (Fc domain) and at some extent is similar to antibody because also has two binding sites that selectively bind another protein - glycoprotein granulocyte colony stimulating factor (GCSF), which was immobilized on a thin gold layer in order to design an immunosensor sensitive to GCSF. Three structurally different GCSF-based proteins were genetically-engineered and evaluated as ligands, which selectively bind to immobilized GCSF-Receptor: (i) GCSF monomer (mGCSF), (ii) GCSF-homodimer consisting of two via polypeptide $L \alpha$-based linker 'fused' GCSF molecules ((GCSF) $2 L \alpha$ ) and (iii) GCSFheterodimer (SCF-L $\alpha$-GCSF), which is based on a native GCSF molecule 'fused' via $L \alpha$-based linker with another protein - a soluble part of stem cell factor (SCF). SCF, unlike GCSF, does not contain any site suitable for GCSF-Receptor binding. The ligands differ by: (i) molecular mass - $(\text { GCSF) })_{2} L \alpha$ and SCF- $L \alpha$-GCSF $F$ are two times heavier than mGCS, (ii) number of binding sites - mGCSF and SCF-L $\alpha$-GCSF have one binding site, while (GCSF) $2 L \alpha$ has two. The binding kinetics of mGCSF, (GCSF) $)_{2} L \alpha$, and SCF-L $\alpha$-GCSF with immobilized GCSFReceptor was investigated using total internal reflection ellipsometry. The interaction kinetics of the mGCSF and SCF-L $\alpha$-GCSF are both well described using a standard Langmuir kinetics model. However, receptor-ligand association and dissociation rates in the case of SCF- $L \alpha-$ GCSF ligand are about 10 times lower than that of mGCSF. The association rate of (GCSF) $2 L \alpha$ 
Z. Balevicius, J. Talbot, L. Tamosaitis, I. Plikusiene, A. Stirke, G. Mickiene, S. Balevicius, A. Paulauskas, A. Ramanavicius. Modelling of immunosensor response: the evaluation of binding kinetics between an immobilized receptor and structurally-different genetically engineered ligands. Sensors and Actuators B Chemical 2019, 297, 126770. DOI:10.1016/j.snb.2019.126770

https://doi.org/10.1016/j.snb.2019.126770

\section{Journal version is available:}

https://www.sciencedirect.com/science/article/abs/pii/S0925400519309700?via\%3Dihub

is about half of that of the mGCSF, which can be explained by the smaller diffusion coefficient of the larger molecule. Moreover, unlike SCF-L $\alpha$-GCSF, the (GCSF) $2 L \alpha$ adsorption kinetics cannot be adequately described by the standard Langmuir kinetics model and surface regeneration (induced by 'washing') experiments illustrate that (GCSF) $2 L \alpha$, unlike the mGCSF and SCF-La-GCSF, is irreversibly bound to the surface modified by immobilized GCSFReceptors. Therefore, to describe binding kinetics in the case of (GCSF) $2 L \alpha$ we have applied advanced kinetic model based on three protein association stages (three-stage kinetics model) in which (GCSF) $2 L \alpha$ forms several different intermediate complexes with GCSF-Receptor. This model precisely describes the time-varying surface concentration of (GCSF) $2 L \alpha$ bound to surface modified by immobilized GCSF-Receptors. In addition to the bioanalytical-aspects possible improvement of GCSF-based drugs is discussed.

KEYWORDS: immunosensor; receptor-ligand interaction; spectroscopic ellipsometry; total internal reflection ellipsometry; granulocyte colony stimulating factor (GCSF); Langmuir kinetics model, three-stage kinetics model.

\section{Graphical Abstract}
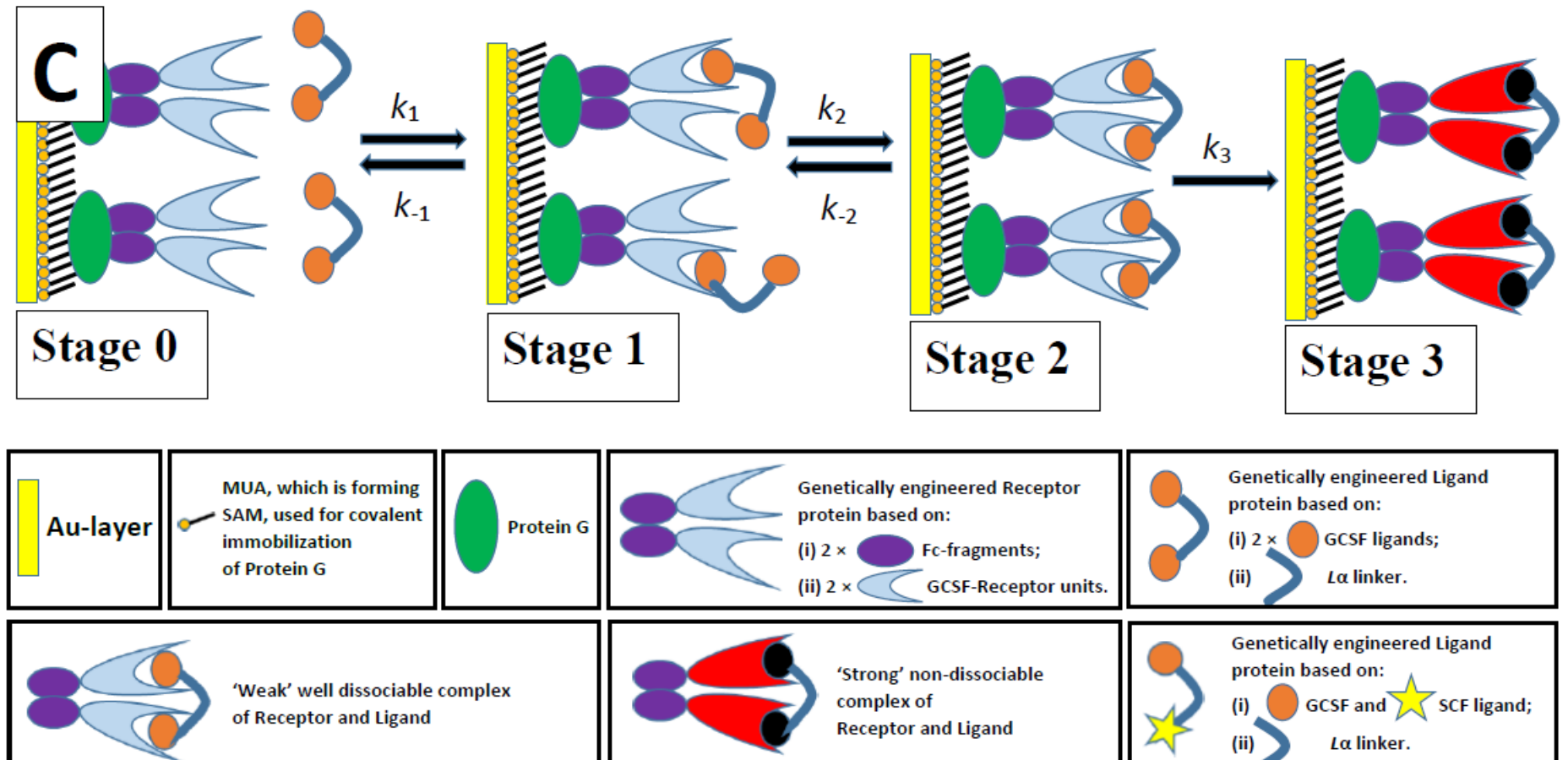

'Weak' well dissociable complex of Receptor and Ligand

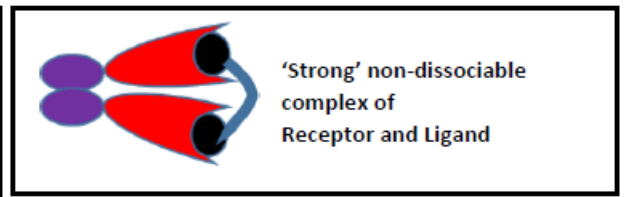

\begin{tabular}{|l} 
Genetically engineered Ligand \\
protein based on: \\
(i) GCSF and 2 SCF ligand; \\
(ii) La linker.
\end{tabular}


Z. Balevicius, J. Talbot, L. Tamosaitis, I. Plikusiene, A. Stirke, G. Mickiene, S. Balevicius, A. Paulauskas, A. Ramanavicius. Modelling of immunosensor response: the evaluation of binding kinetics between an immobilized receptor and structurally-different genetically engineered ligands. Sensors and Actuators B Chemical 2019, 297, 126770. DOI:10.1016/j.snb.2019.126770

https://doi.org/10.1016/j.snb.2019.126770

Journal version is available:

https://www.sciencedirect.com/science/article/abs/pii/S0925400519309700?via\%3Dihub

\section{Introduction}

Immunosensors are bioanalytical devices that are based on the interaction of proteins: one protein is immobilized on the surface and acts as a receptor and another one (analyte) is present in the sample solution and acts as a ligand, which specifically binds with the immobilized receptor [1]. Substantial progress in the development of modern optical $[2,3,4]$, electrochemical $[5,6,7,8]$ calorimetric $[9,10]$ acoustic $[11,12]$ and mass variation $[13,14]$ immunosensors has occurred during the past few years. Both the kinetics of receptor-ligand interaction and the strength of receptor-ligand complex are very important in the development of immunosensors, because both characteristics are directly related to the immunosensor's response and the regeneration time. On the other hand, the strength of receptor-ligand complex, which is defined by association/dissociation constants and/or by residence time, determines the analytical signal and reusability related aspects of the immunosensor. In the most cases, when receptor-ligand complex lifetime (residence time) is very long, then the regeneration of immunosensor after the registration of analytical signal becomes more complicated and/or it lasts longer. It should be noted that the residence time is also critical in the formation of receptor-ligand complex. Therefore, the evaluation of complex residence time is exploited in various biotechnological and biomedical applications, e.g.; the duration of the biological effect induced by a receptor-ligand complex is directly related to the residence time of the complex itself [15]. Therefore, the duration of ligand interaction with its receptor is important for the durability of biological effect [16].

The residence time of a receptor-ligand complex is characterized by the reciprocal of the dissociation rate constant [15,17]. We noted in our previously published research [18], the residence time should be taken into account during the development and optimization of biopharmaceuticals based on glycoprotein granulocyte colony stimulating factor (GCSF) whose molecular weight is $\sim 20 \mathrm{kDa}$. GCSF is a protein acting as cytokine, which increases the number of the hematopoietic stem cells in blood and also stimulates neutrophils maturation. Unfortunately, this type of cytokines has a low physiological residence time in vivo. For this reason, the creation and testing of different kinds of new, second generation GCSF-based drugs, having better pharmacodynamics and pharmacokinetics, has been the object of intensive investigation. A typical example of the problem is related to the application of low molecular recombinant forms of GCSF, which are widely used in medicine after chemotherapy to increase the number of neutrophils and to cure chronic neutropenia [19]. One of the ways to decrease the drug clearance from the organism is to design a higher molecular weight drug, consisting of several basic molecules (monomers). Moreover, recent developments in recombinant protein fusion technology enable to overcome the short action-time of some therapeutic proteins and, at the same time, they add some extra functionality to newly developed protein based drugs [20,21]. However, the interaction of this more complicated protein-based drug with the corresponding receptor, which binds the drug, should be determined and evaluated. Therefore, receptor-ligand interaction based analytical systems, which are suitable for the determination of both the concentration of proteinbased drug and the evaluation of receptor-ligand dissociation kinetics, are required. Immunoanalytical systems including immunosensors are the most suitable for the evaluation of both the above mentioned tasks. Therefore, in present research, we have developed and 
Z. Balevicius, J. Talbot, L. Tamosaitis, I. Plikusiene, A. Stirke, G. Mickiene, S. Balevicius, A. Paulauskas, A. Ramanavicius. Modelling of immunosensor response: the evaluation of binding kinetics between an immobilized receptor and structurally-different genetically engineered ligands. Sensors and Actuators B Chemical 2019, 297, 126770. DOI:10.1016/j.snb.2019.126770

https://doi.org/10.1016/j.snb.2019.126770

Journal version is available:

https://www.sciencedirect.com/science/article/abs/pii/S0925400519309700?via\%3Dihub

characterized the action of an immunosensor, which is suitable: (i) for the determination of several genetically engineered GCSF-based compounds and (ii) for the modelling of interaction between GCSF-Receptor (in schemes and figures it is abbreviated as GCSF-R) and GCSF-based drugs, which specifically bind to the GCSF-Receptor.

Another important issue in the creation of immunosenors is the choice of the most suitable signal transduction principle. For determination of receptor-ligand interaction, surface plasmon resonance (SPR) based optical immunosensors are widely used due to high sensitivity of SPRbased methods [22]. In this regard the combination of spectroscopic ellipsometry and the SPR phenomenon, which usually is called as total internal reflection ellipsometry (TIRE), is an even more promising technique [23]. According to our experience TIRE provides even better sensitivity towards surface changes, when compared with traditional SPR in intensity interrogation modes $[18,24,25]$. Due to high sensitivity TIRE is suitable for the evaluation of receptor-ligand interaction in situ, because TIRE does not require the application of any kind of analytical labels and is nondestructive. This method is also suitable for the determination of kinetic features of various biochemical interactions, e.g.: antibody-antigen interactions. TIRE is also well suited to the determination of 'the surface-adsorbed mass', e.g., the surface concentration of adsorbed proteins. The high-sensitivity of TIRE enables one to analyze in detail the structure and properties of thin protein-based layers $[18,24,25]$ during their formation, thereby providing information about the receptor-ligand conformational changes. In addition, TIRE can be applied in the modelling of protein-based layer formation processes. Since TIRE can be applied for receptor-ligand complex formation measurements in situ it is suitable for the calculation of interaction kinetic constants from which we can extract information about receptor-ligand association/dissociation and calculate the residence time of each intermediate complex formed during receptor-ligand interaction. As it has been noted earlier by Tummino and Copeland [17], a quantitative evaluation of the residence time is an important part of the overall study of the receptor-ligand interaction, especially in the case of such receptor-ligand association processes, when several transient stages are involved in the formation of receptor-ligand complex.

In this work, we have designed an immunosensor based on an immobilized GCSFReceptor. The dynamic spectroscopic TIRE method was applied for in situ registration of the analytical signal generated by this immunosensor. The interaction kinetics of three structurallydifferent homologues of genetically engineered GCSF ligands with the immobilized GCSFReceptor was evaluated. Three structurally different ligands were applied: (i) GCSF monomer (mGCSF) (ii) GCSF-homodimer consisting of two via $L \alpha$ linker 'fused' GCSF molecules $\left((\mathrm{GCSF})_{2} L \alpha\right)$ and (iii) GCSF-heterodimer (SCF-L $\alpha$-GCSF), which was based on native GCSF molecule via $L \alpha$ linker 'fused' with other protein - a soluble part of stem cell factor (SCF). The mGCSF and SCF-L $\alpha$-GCSF possess one GCSF-based binding site, while (GCSF) 2 L $\alpha$ contains two GCSF-based binding sites accessible for the GCSF-Receptor. Modeling of receptor-ligand interaction was performed using (i) standard Langmuir kinetics model and (ii) advanced kinetic model based on three protein association stages (three-stage kinetics model). Significant attention was paid to the involvement of several transition stages and the evaluation of residence time of each stage. 
Z. Balevicius, J. Talbot, L. Tamosaitis, I. Plikusiene, A. Stirke, G. Mickiene, S. Balevicius, A. Paulauskas, A. Ramanavicius. Modelling of immunosensor response: the evaluation of binding kinetics between an immobilized receptor and structurally-different genetically engineered ligands. Sensors and Actuators B Chemical 2019, 297, 126770. DOI:10.1016/j.snb.2019.126770

https://doi.org/10.1016/j.snb.2019.126770

Journal version is available:

https://www.sciencedirect.com/science/article/abs/pii/S0925400519309700?via\%3Dihub

\section{EXPERIMENTAL PART}

\subsection{Chemicals, consumables and proteins}

All salts and other basic chemicals were purchased from Sigma-Aldrich and were of analytical grade. 11-Mercaptoundecanoic acid (11-MUA) 98\%, N-hydroxysuccinimide (NHS), N-(3dimethylaminopropyl)-N'-ethylcarbodiimide hydrochloride (EDC) and protein $\mathrm{G}$ (Protein-G) were also purchased from Sigma-Aldrich. The recombinant extracellular domain of the human granulocyte colony-stimulating factor receptor protein fused with a human Fc region of IgG1 (GCSF-Receptor) was purchased from Abcam (Cambridge, UK).

Structurally different GCSF-based ligands - mGCSF, (GCSF) $2 L \alpha$ ) and SCF-L $\alpha$-GCSF were developed and genetically engineered by Profarma UAB (Vilnius, Lithuania). The mGCSF and SCF-L $\alpha$-GCSF possessed one binding site, while (GCSF) ${ }_{2} L \alpha$ contained two binding sites accessible for GCSF-Receptor (GCSF-R). In dimeric GCSF-based derivatives (homodimeric (GCSF) $2 L \alpha$ and heterodimeric - (SCF- $L \alpha$-GCSF) the same $L \alpha$-linker was applied for the 'fusion' of: (i) two GCSF molecules in the case of (GCSF) $2 L \alpha$ and (ii) SCF and GCSF molecules in the case of (SCF-L $\alpha$-GCSF). The molecular mass and dimensions of GCSF-based ligands are following: (i) monomeric mGCSF is of $19 \mathrm{kDa}$ and of $4.86 \times 2.9 \times 3.48 \mathrm{~nm}$; homodimeric (GCSF) $2 L \alpha$ of $42.5 \mathrm{kDa}$ and of $4.86 \times 2.9 \times 11.8 \mathrm{~nm}$ and, heterodimeric SCF-L $\alpha$-GCSF of $42.38 \mathrm{kDa}$ and of $4.86 \times 2.9 \times 11.8 \mathrm{~nm}$. (See: $\mathrm{http}: / / \mathrm{pdb} .0 \mathrm{rg} / \mathrm{pdb} / \mathrm{explore} / \mathrm{explore} . \mathrm{do}$ ?structureld=2D9Q) The methods used to prepare and to purify the homodimeric GCSF and heterodimeric GCSF ligands are presented in our previuos research [20,21]. Ultrapure water was used for all experiments.

BK7 glass slide of $1 \mathrm{~mm}$ thickness, which was covered by $\mathrm{Cr}$-Au layer (BK7-glass/Cr-Au), was purchased from XanTec bioanalytics $\mathrm{GmbH}$ (Duesseldorf, Germany). Refraction index matching fluid was purchased from Cargille Ltd. (New York, USA).

\subsection{Development of immunosensor: the modification of sensing surface and the immobilization of proteins}

Commercially available BK7-glass/Cr-Au slide from XanTecbioanalytics $\mathrm{GmbH}$ (Duesseldorf, Germany), which usually is used as chip for Surface plasmon resonance measurements, based on $\mathrm{Cr}$ coated glass slide with deposited Au layer was used for the design of sensing part of immunosensor and it was used for all here described Elipsometric measurements. Some details how BK7-glass/Cr-Au slide was designed: (i) in order to form the Cr-Au layer over Bk7-glass, it was covered by $2 \mathrm{~nm}$ sublayer of chromium (in order to improve the adhesion between Bk7 glass and gold layer) and then (ii) a $50 \mathrm{~nm}$ thick layer of gold was deposited using magnetron based sputtering technology. Before further use the BK7-glass/Cr-Au was pretreated by chemical cleaning with piranha solution (consisting of $1 / 3$ peroxide, $2 / 3$ sulphuric acid) for 2 minutes and then it was rinsed in ethanol and then in ultrapure water. After this, the BK7-glass/Cr-Au slide was incubated in $1 \mathrm{mM} 11$-mercaptoundecanoic acid (11-MUA) solution in ethanol for 18 hours and a self-assembled monolayer (SAM) was formed over $\mathrm{Cr}$-Au layer. Further the BK7-glass/Cr-Au slide modified by SAM consisting of 11-MUA (BK7-glass/Cr-Au/MUA) was rinsed with ethanol, later - with ultrapure water and then dried using argon gas. Then carboxyl groups of 11-MUA 
Z. Balevicius, J. Talbot, L. Tamosaitis, I. Plikusiene, A. Stirke, G. Mickiene, S. Balevicius, A. Paulauskas, A. Ramanavicius. Modelling of immunosensor response: the evaluation of binding kinetics between an immobilized receptor and structurally-different genetically engineered ligands. Sensors and Actuators B Chemical 2019, 297, 126770. DOI:10.1016/j.snb.2019.126770

https://doi.org/10.1016/j.snb.2019.126770

Journal version is available:

https://www.sciencedirect.com/science/article/abs/pii/S0925400519309700?via\%3Dihub

were activated using the solution of $0.1 \mathrm{M} \mathrm{N}$-hydroxysuccinimide (NHS) and $0.4 \mathrm{M} \mathrm{N}$-(3dimethylaminopropyl)-N'-ethylcarbodiimide hydrochloride (EDC). To achieve this activation of carboxyl groups a freshly prepared solution of $0.1 \mathrm{M} \mathrm{NHS}$ and $0.4 \mathrm{M}$ EDC was injected into the cylindrical shape cell (diameter $3.5 \mathrm{~mm}$, height $1 \mathrm{~mm}$ ) and incubated for 5 minutes.

For further modification of BK7-glass/Cr-Au slide was mounted inside of home-made flowthrough-cell (TIRE-cell), which was used for all here described TIRE measurements. TIRE-cell then was rinsed with a $10 \mathrm{mM}$ sodium acetate buffer, $\mathrm{pH}$ 4.0. When a steady-state TIRE signal was achieved, then a solution of $100 \mu \mathrm{g} / \mathrm{ml}$ of Protein-G in10 mM sodium acetate buffer, $\mathrm{pH} 4.0$, was added into TIRE-cell. After $33 \mathrm{~min}$ of incubation, a steady-state TIRE signal was achieved indicating that the structure based on BK7-glass/Cr-Au/MUA covered by Protein-G layer (BK7glass/Cr-Au/MUA/Protein-G) had been formed. Then the BK7-glass/Cr-Au/MUA/Protein-G slide was again rinsed with sodium acetate buffer, $\mathrm{pH} 4.0$ and later BK7-glass/Cr-Au/MUA/Protein-G slide was treated with $1 \mathrm{M}$ ethanolamine hydrochloride, $\mathrm{pH} 8.5$, for 15 min to block the remaining unbound activated carboxyl groups. Then non-covalently bounded Protein-G was removed by

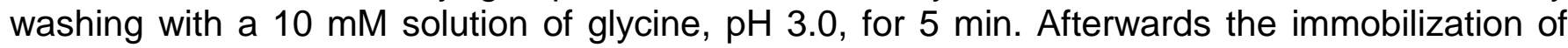
GCSF-Receptor having $10.4 \mathrm{~nm} \times 7.2 \mathrm{~nm}$ dimensions was performed by a 33 minutes incubation of the BK7-glass/Cr-Au/MUA/Protein-G slide in phosphate buffer solution (PBS), $\mathrm{pH} 7,4$, containing $10 \mathrm{mg} / \mathrm{ml}$ of GCSF-Receptor, $140 \mathrm{mM}$ of $\mathrm{NaCl}, 2,7 \mathrm{mM}$ of $\mathrm{KCl}, 10 \mathrm{mM}$ of $\mathrm{K}_{3} \mathrm{PO}_{4}$. GCSF-Receptor was non-covalently attached to covalently immobilized Protein-G, which specifically binds the GCSF-Receptor via the Fc subunit. Finally, the formed BK7-glass/CrAu/MUA/Protein-G/GCSF-R slide was washed with PBS solution, $\mathrm{pH} 7,4$, in order to remove unbounded GCSF-Receptor.

\subsection{Apparatus}

A spectral ellipsometer M-2000X J.A.Woollam (Lincoln, USA) with rotating compensator, BK7 $70^{\circ}$ glass prism and $1 \mathrm{~mm}$ thick BK7 glass slide (BK7-glass), was used to investigate receptor-ligand interaction. It was used in dynamic acquisition mode to measure the evolution of ellipsometric parameters 'Psi' $(\Psi(\lambda))$ and 'Delta' $(\Delta(\lambda))$ in real-time. A glass prism BK7 $70^{\circ}$ was installed in the optical pathway of ellipsometer. During ellipsometric measurements BK7-glass/CrAu/MUA/Protein-G/GCSF-R slides were attached to the prism by refraction index matching fluid purchased from Cargille Ltd. (New York, USA). The formation of BK7-glass/Cr-Au/MUA/ProteinG/GCSF-R slide is described in section 2.2. Then the prism with attached BK7-glass/CrAu/MUA/Protein-G/GCSF-R slides was placed into a TIRE-cell made from teflon and filled with PBS, $\mathrm{pH} 7.4$.

\subsection{Evaluation of immunosensor signal}

The TIRE measurements were performed in the spectral range from $300 \mathrm{~nm}$ until $1000 \mathrm{~nm}$. The surface plasmon waves were excited at an external angle of incidence equal to $70^{\circ}$ for $\mathrm{Bk} 7$ glass/Cr-Au/MUA and Bk7-glass/Cr-Au/MUA/Protein-G samples. In the SPR spectra, a dip in $\Psi(\lambda)$ and strong changes in $\Delta(\lambda)$ were observed at $660 \mathrm{~nm}$ and $658 \mathrm{~nm}$, respectively. During the TIRE measurements, all the steps of the receptor (Bk7-glass/Cr-Au/MUA/Protein-G/GCSF-R) binding with mGCSF, (GCSF) ${ }_{2} L \alpha$ and SCF- $L \alpha-G C S F$ were performed by injecting ligand- 
Z. Balevicius, J. Talbot, L. Tamosaitis, I. Plikusiene, A. Stirke, G. Mickiene, S. Balevicius, A. Paulauskas, A. Ramanavicius. Modelling of immunosensor response: the evaluation of binding kinetics between an immobilized receptor and structurally-different genetically engineered ligands. Sensors and Actuators B Chemical 2019, 297, 126770. DOI:10.1016/j.snb.2019.126770

Journal version is available:

https://www.sciencedirect.com/science/article/abs/pii/S0925400519309700?via\%3Dihub

containing solutions into TIRE-cell with a syringe-pump. In order to achieve good repeatability, the temperature of the buffer solution was kept constant and was equal $23 \pm 0.1^{\circ} \mathrm{C}$ and dynamic response of four measurements with the same ligand concentration were performed. The final experimental ellipsometric data was the average of these measurements. Data were analyzed using a data acquisition program Complete Ease from J.A. Woollam Co. Inc., (Lincoln, USA). TIRE data were analyzed using a multi-layer model and regression analysis to determine refractive index dispersion and the thickness of formed layers. The Bruggeman EMA was used for kinetic data analysis as well as for the analysis of layers when steady-state conditions were reached. For the evaluation of in situ data, the value of the effective refractive index was chosen in between that of surface maximally covered by protein-based layer and that of a buffer solution. The change of effective refractive index over time was transformed to the change of fill factor $(F)$ of formed protein layers, which was calculated as $F=n(t) / n_{\mathrm{st}}$, here $n(t)$ is refractive index at each time instance and $n_{\text {st }}$ is refractive index at stead-state conditions after full formation of the monolayer with surface density $\approx 8.25 \cdot 10^{-8} \mathrm{~g} / \mathrm{cm}^{2}$. The binding kinetics of the GCSF-based proteins was measured using a $10 \mu \mathrm{g} / \mathrm{ml}$ PBS buffer, $\mathrm{pH}$ 7.4. The regeneration (washing) of the protein layer was performed by replacing the PBS buffer with a $10 \mathrm{mM}$ solution of glycine, pH 3.0.

\section{RESULTS AND DISCUSSION}

The kinetics of mGCSF ligand binding to GCSF-Receptor immobilized on a Bk7-glass/CrAu/MUA/Protein-G/GCSF-R slide is presented in figure 1. The inset of figure 1 shows the reverse process, i.e. the dissociation of GCSF-R/mGCSF complex during 'washing' with glycine solution. 
Z. Balevicius, J. Talbot, L. Tamosaitis, I. Plikusiene, A. Stirke, G. Mickiene, S. Balevicius, A. Paulauskas, A. Ramanavicius. Modelling of immunosensor response: the evaluation of binding kinetics between an immobilized receptor and structurally-different genetically engineered ligands. Sensors and Actuators B Chemical 2019, 297, 126770. DOI:10.1016/j.snb.2019.126770

https://doi.org/10.1016/j.snb.2019.126770

Journal version is available:

https://www.sciencedirect.com/science/article/abs/pii/S0925400519309700?via\%3Dihub

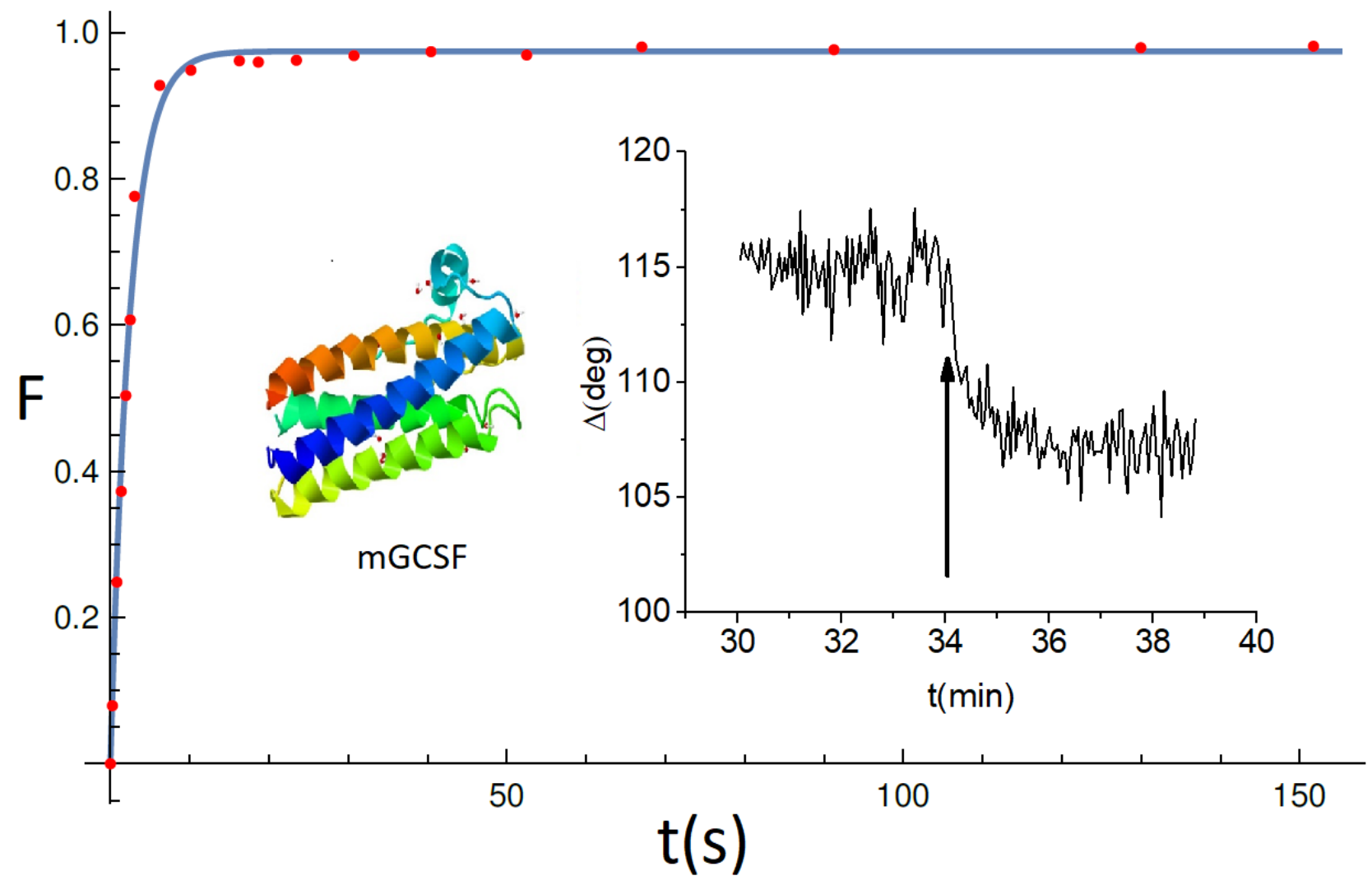

Fig. 1. Relative (normalized to the maximum value) surface concentration of mGCSF molecules bound to the Bk7-glass/Cr-Au/MUA/Protein-G/GCSF-R slide vs time. The solid line represents the fit of the standard Langmuir kinetic model with $k_{a(m)}=7.5 \cdot 10^{5} \mathrm{M}^{-1} \mathrm{~s}^{-1} ; k_{\mathrm{d}(\mathrm{m})}=0.0105 \mathrm{~s}^{-1}$. Inset. Variation ellipsometric parameter $\Delta$ with time before and after the 'washing' of Bk7-glass/CrAu/MUA/Protein-G/GCSF-R/mGCSF with glycine solution. The arrow shows the start of the washing procedure. 
Z. Balevicius, J. Talbot, L. Tamosaitis, I. Plikusiene, A. Stirke, G. Mickiene, S. Balevicius, A. Paulauskas, A. Ramanavicius. Modelling of immunosensor response: the evaluation of binding kinetics between an immobilized receptor and structurally-different genetically engineered ligands. Sensors and Actuators B Chemical 2019, 297, 126770. DOI:10.1016/j.snb.2019.126770

\section{Journal version is available:}

https://www.sciencedirect.com/science/article/abs/pii/S0925400519309700?via\%3Dihub

As can be seen from figure 1 , reaching steady-state conditions in the formation of the GCSF-R/mGCSF complex formed on Bk7-glass/Cr-Au/MUA/Protein-G/GCSF-R slide takes place within 20 seconds. In contrast, the GCSF-R/mGCSF complex dissociation process is significantly slower about 2.5 minutes requiring to achieve the steady-state conditions (Fig. 1 inset). The investigation of SCF- $\alpha$-GCSF association with and dissociation from immobilized GCSF-Receptor (Fig. 2) demonstrated that both the association and dissociation processes are significantly slower in comparison with that of mGCSF. The steady-state equilibrium of GCSFR/SCF-L $\alpha$-GCSF complex formation was reached after 180 seconds. The dissociation process of the GCSF-R/SCF-L $\alpha$-GCSF complex takes about 15 minutes (Fig. 2, inset), which is significantly slower in comparison to that of the GCSF-R/mGCSF complex.

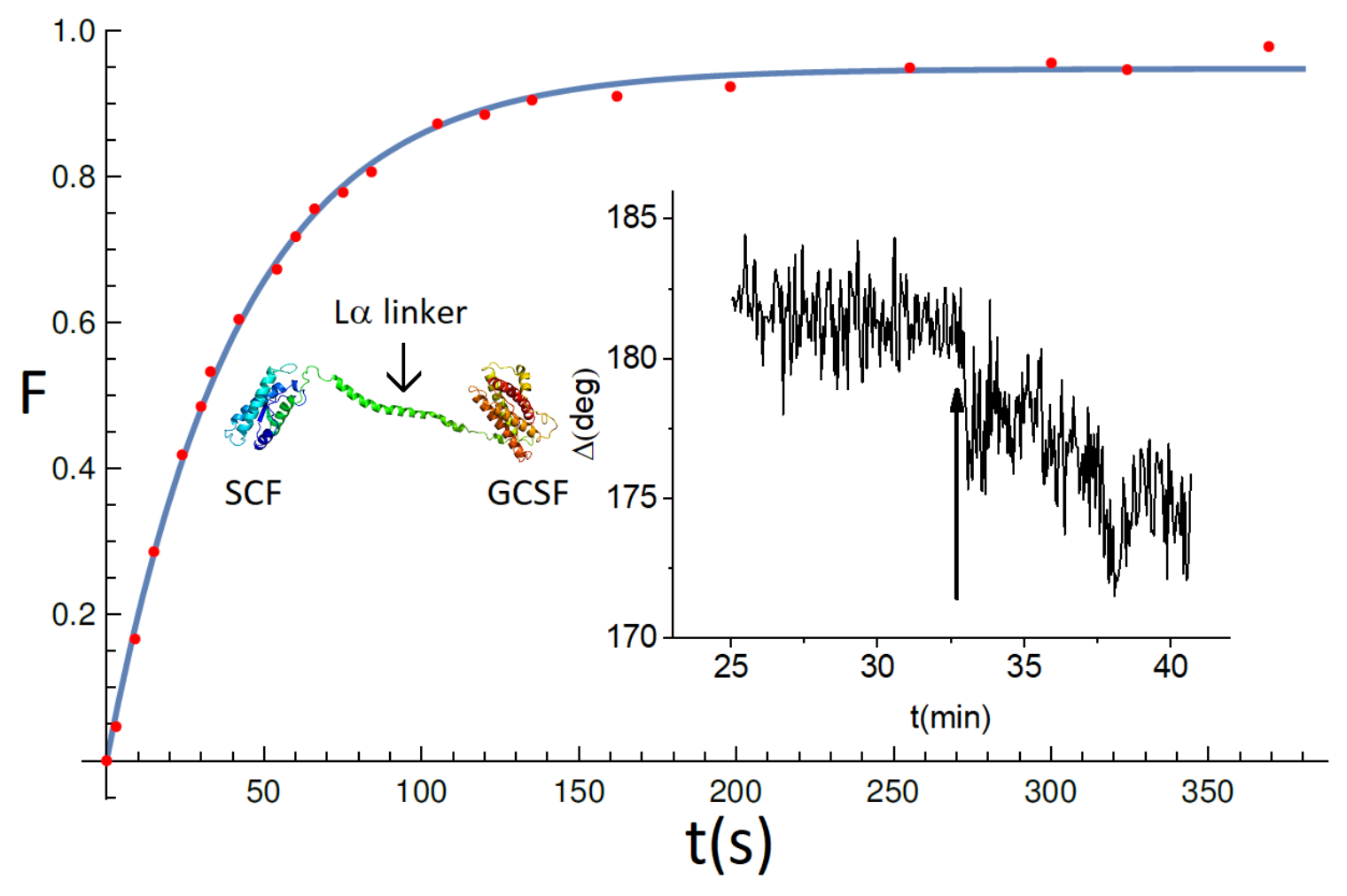

Fig. 2. Relative (normalized to the maximum value) surface concentration of SCF-L $\alpha$-GCSF molecules bound to the Bk7-glass/Cr-Au/MUA/Protein-G/GCSF-R slide vs time. The solid line represents the fit of the standard Langmuir kinetic model with $k_{\text {and }}=8.5 \cdot 10^{4} \mathrm{M}^{-1} \mathrm{~s}^{-1}$, $k_{\text {ahd }}=0.00125$ $\mathrm{s}^{-1}$. Inset. Variation of ellipsometric parameter $\Delta$ with time before and after the 'washing' of Bk7glass/Cr-Au/MUA/Protein-G/GCSF-R/ mGCSF with glycine solution. The arrow shows the start of the washing procedure. 
Z. Balevicius, J. Talbot, L. Tamosaitis, I. Plikusiene, A. Stirke, G. Mickiene, S. Balevicius, A. Paulauskas, A. Ramanavicius. Modelling of immunosensor response: the evaluation of binding kinetics between an immobilized receptor and structurally-different genetically engineered ligands. Sensors and Actuators B Chemical 2019, 297, 126770. DOI:10.1016/j.snb.2019.126770

https://doi.org/10.1016/j.snb.2019.126770

\section{Journal version is available:}

https://www.sciencedirect.com/science/article/abs/pii/S0925400519309700?via\%3Dihub

Very different kinetics of dimeric (GCSF) 2 L $\alpha$ ligand binding to immobilized GCSF-Receptor was observed (Fig. 3): the steady-state equilibrium in the formation of GCSF-R/(GCSF) $2 L \alpha$ complex based layer was achieved after approximately 50 seconds. However, contrary to the results presented in figures 1 and 2, no changes were observed when glycine solution was added into TIRE-cell in order to dissociate GCSF-R/(GCSF) ${ }_{2} L \alpha$ complex (Fig. 3). This confirms that the association of GCSF-Receptor with (GCSF) $2 \alpha \alpha$ is significantly stronger than that with mGCSF or SCF-La-GCSF.

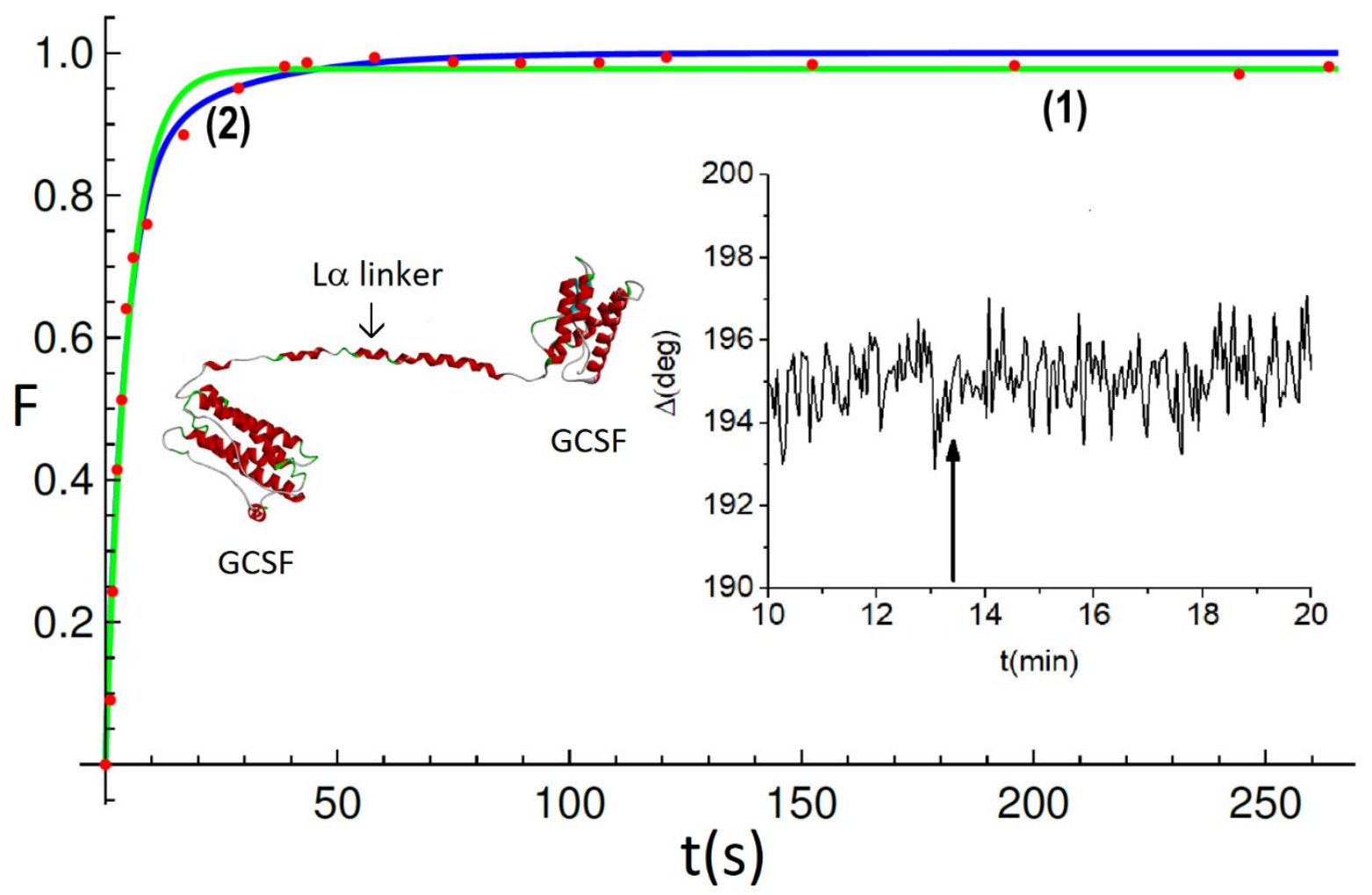

Fig. 3. Relative (normalized to the maximum value) surface concentration of (GCSF) $2 L \alpha$ molecules bound to Bk7-glass/Cr-Au/MUA/Protein-G/GCSF-R slide vs time. The solid lines represent fits using: the standard Langmuir kinetics (green curve (1)) and advanced kinetic model based on three protein association stages (three-stage kinetics model) (blue curve (2)); interaction rate constants calculated using the three-stage kinetics model based fit with experimental data: $k_{a(d)}=4 \cdot 10^{5} \mathrm{M}^{-1} \mathrm{~s}^{-1}, k_{2}=142.27 \mathrm{~s}^{-1}, k_{-1}=1.3544 \mathrm{~s}^{-1}, k_{3}=0.0496 \mathrm{~s}^{-1}$. Inset. Variation of ellipsometric parameter $\Delta$ before and after the 'washing' with glycine solution. The arrow shows the start of the washing procedure.

The interaction between proteins (including receptor-ligand interaction) is a complex and multistep process. Therefore, for the evaluation of such process a particular interaction model should be adapted. It should be noted that even the relatively simple adsorption of proteins on 
Z. Balevicius, J. Talbot, L. Tamosaitis, I. Plikusiene, A. Stirke, G. Mickiene, S. Balevicius, A. Paulauskas, A. Ramanavicius. Modelling of immunosensor response: the evaluation of binding kinetics between an immobilized receptor and structurally-different genetically engineered ligands. Sensors and Actuators B Chemical 2019, 297, 126770. DOI:10.1016/j.snb.2019.126770

https://doi.org/10.1016/j.snb.2019.126770

Journal version is available:

https://www.sciencedirect.com/science/article/abs/pii/S0925400519309700?via\%3Dihub

any surface is a multistep process and at least five major steps should be taken into account in the basic description of protein adsorption mechanism [26,27,28]: (i) the transport of the ligand molecule to the binding surface, (ii) initial binding/attachment step, (iii) the rearrangement of the conformation of the adsorbed molecule by their better adaptation to the 'microenvironment', which can lead to stronger or even irreversible binding, (iv) the dissociation/detachment step, and (v) the diffusion away from the surface. Depending on the nature of the protein, surface and ambient conditions the adsorption can be fully reversible, partially irreversible or completely irreversible. The same major steps can be incorporated in models of receptor-ligand interaction.

Two models were used for the analysis of experimental results: (i) standard - fully reversible Langmuir kinetics model and (ii) advanced kinetic model based on three protein association stages (three-stage kinetics model). In both models we have taken into consideration that the source of ligands in the TIRE-cell is discontinuous. This assumption was based on the estimation of total number of ligands in TIRE-cell volume and maximal number of proteins, which can be bonded by the receptors immobilized on Bk7-glass/Cr-Au/MUA/Protein-G/GCSF-R slide. As each receptor has 2 binding sites the total number of these sites on the Bk7-glass/CrAu/MUA/Protein-G/GCSF-R slide is about $2.56 \cdot 10^{9}$. Meanwhile in the case of analyte concentration $10 \mu \mathrm{g} / \mathrm{cm}^{3}$ the total number of analyte molecules in TIRE-cell is about $3 \cdot 10^{19}$. This means that the number of ligands bounded to the receptors is $10^{10}$ times lower than the total number of ligands in TIRE-cell volume and, therefore, in calculations the ligand (analyte) source can be applied as 'unlimited source'. The fact that the process of ligand association with receptor theoretically can be diffusion limited or at least significantly affected was strong argument to assess the influence of diffusion to interaction kinetics. Therefore, we have evaluated average time $(I \mathrm{~d})$ during which single protein molecule passes the mean diffusion distance $(L)$ between proteins molecules in the water solution was estimated. After that average time $(I d)$ was compared with experimentally obtained characteristic association time $\left(I_{\mathrm{c}}\right)$ during the receptor-ligand complex formation process. The estimation was performed using Fick's law $T_{\mathrm{d}}=L^{2} / D$ and relation between mean diffusion distance $L$ and ligand concentration:

$$
L=(3 / 4 \pi n)^{1 / 3}
$$

where $D$ is analyte diffusion coefficient in water (for the most of proteins $D \approx 10^{-6} \mathrm{~cm}^{2} / \mathrm{s}$ ), $n$ is number of analyte molecules per volume unit.

It was determined that for $10 \mu \mathrm{g} / \mathrm{cm}^{3}$ ligand concentration $L \approx 10^{-5} \mathrm{~cm}$ and $T_{\mathrm{d}} \approx 86 \mu \mathrm{s}$. Experimental results presented in figures 1-3 shows that $T_{c}$ ranged from $5 \mathrm{~s}$ to $100 \mathrm{~s}$, which is significantly longer then estimated $T$ d value. Significant differences between $\underline{I_{c}}$ and $\underline{I d}$ values illustrates that the receptor-ligand association process in not diffusion limited and, therefore, it can be analysed using both Langmuir kinetic model and the advanced kinetic model based on three protein association stages (three-stage kinetics model) developed in this research.

The interaction of mGCSF and SCF-L $\alpha$-GCSF with an immobilized GCSF-Receptor is mostly a reversible processes, because a significant decrease of surface concentration of ligand bonded to immobilized GCSF-Receptor was observed during the 'washing' procedure, which was performed by the incubation of Bk7-glass/Cr-Au/MUA/Protein-G/GCSF-R/mGCSF and Bk7- 
Z. Balevicius, J. Talbot, L. Tamosaitis, I. Plikusiene, A. Stirke, G. Mickiene, S. Balevicius, A. Paulauskas, A. Ramanavicius. Modelling of immunosensor response: the evaluation of binding kinetics between an immobilized receptor and structurally-different genetically engineered ligands. Sensors and Actuators B Chemical 2019, 297, 126770. DOI:10.1016/j.snb.2019.126770

https://doi.org/10.1016/j.snb.2019.126770

\section{Journal version is available:}

https://www.sciencedirect.com/science/article/abs/pii/S0925400519309700?via\%3Dihub

glass/Cr-Au/MUA/Protein-G/GCSF-R/SCF-La-GCSF slides in glycine solution. In order to simplify the mathematical description in both these cases, some previously mentioned steps (particularly 'step i' 'the transport of the ligand molecule to the surface of Bk7-glass/Cr-Au/MUA/ProteinG/GCSF-R slide and 'step $v$ ' the diffusion away from the surface) were not taken into consideration and the analysis of kinetics was performed using the standard Langmuir kinetics model:

$$
\rho_{(\mathrm{t})}=k_{\mathrm{a}} /\left(k_{\mathrm{a}}+k_{\mathrm{d}}\right)\left[1-\mathrm{e}^{-\left(k_{\mathrm{a}+} k_{\mathrm{d}} t\right.}\right]
$$

where $\rho_{(\mathrm{t})}$ is a fraction of occupied interaction sites at time moment $\mathrm{t}, k_{\mathrm{a}}$ is the association constant $k_{\mathrm{d}}$ is the dissociation constant, $t$ is the duration of experiment until the time moment $\mathrm{t}$.

The modelling (solid lines in Figs. 1 and 2) shows that in the case of the interaction of immobilized GCSF-Receptor with $\mathrm{mGCSF}$, the association and dissociation constants are $k_{a}(\mathrm{~m})=$ $7.5 \times 10^{5} \mathrm{M}^{-1} \mathrm{~s}^{-1}$ and $k_{\mathrm{d}(\mathrm{m})}=0.0105 \mathrm{~s}^{-1}$, respectively. The characteristic residence time calculated from the $k_{d(m)}$ value is $\approx 95 \mathrm{~s}$, which is in good agreement with GCSF-R/mGCSF dissociation experiment (Fig. 1, inset).

The kinetic analysis of SCF-L $\alpha$-GCSF binding to immobilized GCSF-Receptor, which is presented in figure 2 , yielded the following values of association and dissociation constants: $k_{a(h d)}$ $=8.5 \times 10^{4} \mathrm{M}^{-1} \mathrm{~s}^{-1}, k_{d}(\mathrm{hd})=0.0012488 \mathrm{~s}^{-1}$, respectively. The calculation of $k_{\mathrm{a}(\mathrm{hd})}$ was performed taking into consideration that only one site of SCF-L $\alpha$-GCSF is involved into formation of complex with GCSF-Receptor. This demonstrates that the association rate of GCSF-Receptor with SCF-L $\alpha$ GCSF is significantly slower than that with mGCSF. Moreover, the characteristic dissociation time of GCSF-R/SCF-L $\alpha$-GCSF is $800 \mathrm{~s}$, which is more than 8 times longer in comparison to that $(95$ s) of GCSF-R/mGCSF. The 'washing' experiment also showed a similar GCSF-R/SCF-L $\alpha$-GCSF complex dissociation process which was about 800-850 s. (Fig. 2, inset).

Efforts to apply the standard Langmuir kinetic model for the description of GCSF$\mathrm{R} /(\mathrm{GCSF})_{2} L \alpha$ complex formation kinetics resulted in a significant deviation from the experimental results (Fig. 3, green curve (1)), while the standard Langmuir kinetic model for the description of GCSF-R/mGCSF and GCSF-R/SCF-L $\alpha$-GCSF complex formation (Fig. 4A, Fig. 4B).

. Moreover, the inset of figure 3 shows that glycine solution is not able to induce observable dissociation of GCSF-R/(GCSF) ${ }_{2} L \alpha$ complex, which indicates that GCSF-Receptor and $(G C S F)_{2} L \alpha$ binding dynamics in this case is only partially reversible process. Therefore, in this case only a fraction of initially formed GCSF-R/(GCSF $)_{2} L \alpha$ complex may dissociate, while after some rearrangements GCSF-R/(GCSF) $2 L \alpha$ complex becomes not dissociable (GCSF$\left.\mathrm{R} / /(\mathrm{GCSF})_{2} L \alpha\right)$ even in glycine solution. The interaction between these proteins (GCSF-Receptor and (GCSF) $2 L \alpha$ ) becomes stronger due to partial unfolding/rearrangement of the proteins and the optimization of their interaction with the binding sites of immobilized GCSF-Receptor. Hence, after initial binding a fraction of (GCSF) $2 L \alpha$ molecules is irreversibly bond to GCSF-Receptor (GCSF$\mathrm{R} / /(\mathrm{GCSF})_{2} L \alpha$ complex). Most probably this effect is observed due to the formation of receptorligand interactions with the second GCSF subunit. Therefore, the replacement of the initial $(\mathrm{GCSF})_{2} L \alpha$ solution by glycine solution has a very weak influence on the dissociation of GCSF$\mathrm{R} / /(\mathrm{GCSF})_{2} L \alpha$ complex. This effect is observed in results of ellipsometric measurements, which showed only moderate differences in the refractive index of the protein-based layer before and 
Z. Balevicius, J. Talbot, L. Tamosaitis, I. Plikusiene, A. Stirke, G. Mickiene, S. Balevicius, A. Paulauskas, A. Ramanavicius. Modelling of immunosensor response: the evaluation of binding kinetics between an immobilized receptor and structurally-different genetically engineered ligands. Sensors and Actuators B Chemical 2019, 297, 126770. DOI:10.1016/j.snb.2019.126770

\section{Journal version is available:}

https://www.sciencedirect.com/science/article/abs/pii/S0925400519309700?via\%3Dihub

after the 'washing' of Bk7-glass/Cr-Au/MUA/Protein-G/GCSF-R/(GCSF) 2 L $\alpha$ slide by glycine solution. In order to describe the formation of the GCSF-R/(GCSF $)_{2} L a$ complex more correctly we have applied (advanced) three stage based mathematical model in which (GCSF) ${ }_{2} L \alpha$ protein is present in complexes ((GCSF-R)-(GCSF $)_{2} L \alpha, \quad(G C S F-R)_{2}=(G C S F)_{2} L \alpha$ and GCSF$\left.\mathrm{R} / /(\mathrm{GCSF})_{2} L \alpha\right)$, which are represented in stages 1-3: 
Z. Balevicius, J. Talbot, L. Tamosaitis, I. Plikusiene, A. Stirke, G. Mickiene, S. Balevicius, A. Paulauskas, A. Ramanavicius. Modelling of immunosensor response: the evaluation of binding kinetics between an immobilized receptor and structurally-different genetically engineered ligands. Sensors and Actuators B Chemical 2019, 297, 126770. DOI:10.1016/j.snb.2019.126770

https://doi.org/10.1016/j.snb.2019.126770

Journal version is available:

https://www.sciencedirect.com/science/article/abs/pii/S0925400519309700?via\%3Dihub

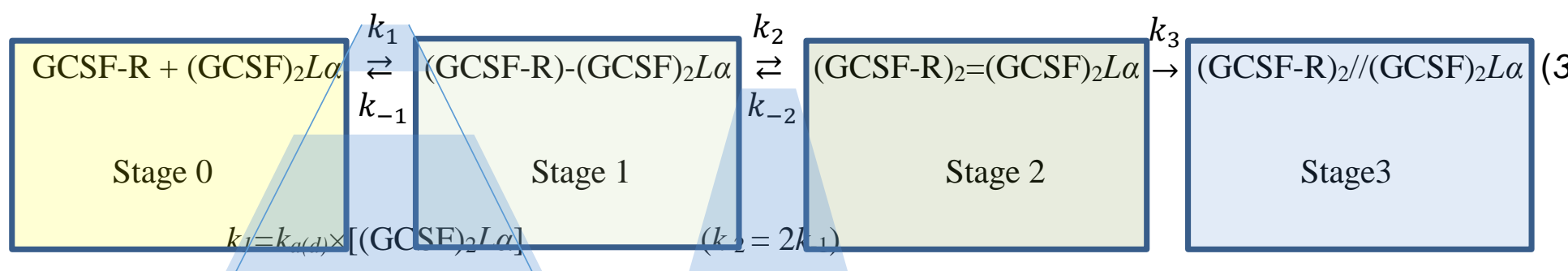

Where: GCSF-R is the immobilized GCSF-Receptor;

(GCSF) ${ }_{2} L \alpha$ is a freely diffusing GCSF dimer (GCSF) $2 L \alpha$;

(GCSF-R)-(GCSF) ${ }_{2} L \alpha$ is a complex of (GCSF) ${ }_{2} L \alpha$ with single GCSF-Receptor;

$(\mathrm{GCSF}-\mathrm{R})_{2}=(\mathrm{GCSF})_{2} L \alpha$ is a complex of $(\mathrm{GCSF})_{2} L \alpha$ with two GCSF-Receptors;

$(\mathrm{GCSF}-\mathrm{R})_{2} / /(\mathrm{GCSF})_{2} L \alpha$ is a complex of $(\mathrm{GCSF})_{2} L \alpha$ with two GCSF-Receptors after the rearrangement of the $(\mathrm{GCSF}-\mathrm{R})_{2}=(\mathrm{GCSF})_{2} L \alpha$ complex into a non-dissociable one ((GCSF$\left.\mathrm{R})_{2} / /(\mathrm{GCSF})_{2} L \alpha\right)$;

$k_{\mathrm{a}(\mathrm{d})}$ - second order association rate constant, which characterizes the first step of association of GCSF- Receptors with (GCSF) $)_{2} L \alpha$ and the formation of the (GCSF-R)-(GCSF) ${ }_{2} L \alpha$ complex;

$k_{1}-$ pseudo-first order association rate constant $\left(k_{1}=k_{a}(d) \times[(G C S F) 2 L \alpha]\right.$; where $k_{a(d)}$ is above mentioned second order association rate constant and $\left[(\mathrm{GCSF})_{2} L \alpha\right]$ is the $(\mathrm{GCSF})_{2} L \alpha$ concentration in solution;

$k_{2}$ - first order association rate constant for the association of a second GCSF ligand of (GCSF-R)-(GCSF) 2 L $\alpha$ complex with a second free GCSF-Receptor;

$k_{3}$ - first order rearrangement rate constant for the rearrangement of dissociable (GCSF$\mathrm{R})_{2}=(\mathrm{GCSF})_{2} L \alpha$ complex into non-dissociable $(\mathrm{GCSF}-\mathrm{R})_{2} / /(\mathrm{GCSF})_{2} L \alpha$ complex;

$k_{-1}$ - first order dissociation rate constant for the dissociation of (GCSF-R)-(GCSF) ${ }_{2} L \alpha$ complex;

k-2 - first order dissociation rate constant for the partial dissociation of (GCSF$\mathrm{R})_{2}=(\mathrm{GCSF})_{2} L \alpha$ complexes $(k-2=2 k-1)$.

It should be noted that the ligand concentration significantly exceeded the immobilized GCSF-Receptor concentration; therefore, only the surface concentration of the (GCSF) ${ }_{2} L \alpha$, which was involved into formation of (GCSF-R)-(GCSF) ${ }_{2} L \alpha, G C S F-R=(G C S F)_{2} L \alpha$ and GCSF$\mathrm{R} / /(\mathrm{GCSF})_{2} L \alpha c o m p l e x e s$, was taken into consideration in the calculations of kinetics.

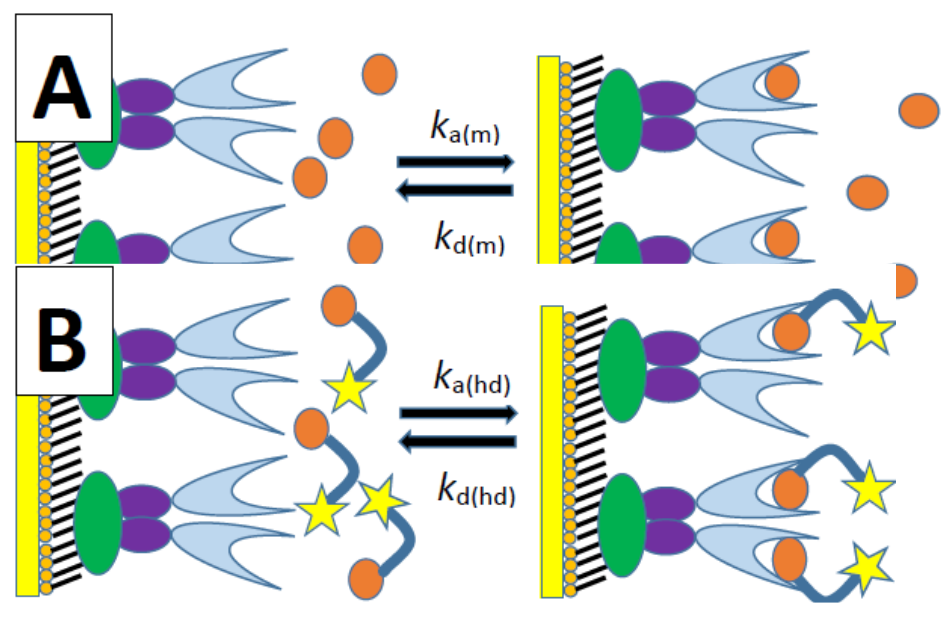


Z. Balevicius, J. Talbot, L. Tamosaitis, I. Plikusiene, A. Stirke, G. Mickiene, S. Balevicius, A. Paulauskas, A. Ramanavicius. Modelling of immunosensor response: the evaluation of binding kinetics between an immobilized receptor and structurally-different genetically engineered ligands. Sensors and Actuators B Chemical 2019, 297, 126770. DOI:10.1016/j.snb.2019.126770

https://doi.org/10.1016/j.snb.2019.126770

Journal version is available:

https://www.sciencedirect.com/science/article/abs/pii/S0925400519309700?via\%3Dihub

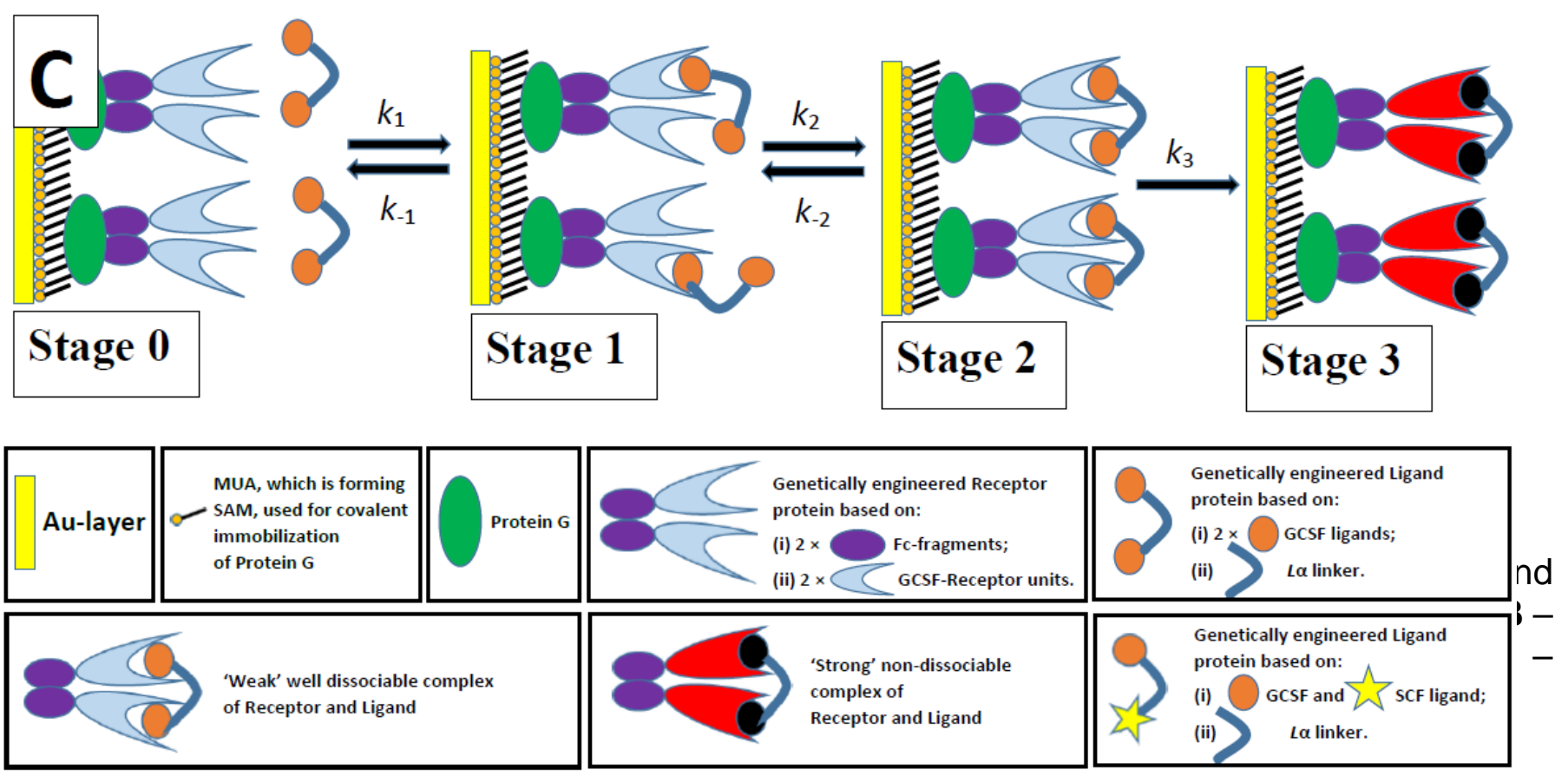

Here applied three-stage kinetic model (Fig. 4C) assumes that in Stage 0 all (GCSF) $2 L \alpha$ is still present in the solution and all GCSF-Receptor sites are free. Stage 1 some (GCSF) $2 L \alpha$ is bound to Bk7-glass/Cr-Au/MUA/Protein-G/GCSF-R slide via one GCSF subunit and a fraction $\left(\rho_{1}\right)$ of '(GCSF $)_{2} L \alpha$ coverage areas' ('coverage areas'), which are theoretically available for binding with (GCSF) ${ }_{2} L \alpha$, is complexed by one ligand-site of (GCSF) $2 L \alpha$ molecule and forms complex, which is denoted as (GCSF-R)-(GCSF) $2 L \alpha$. In Stage 2 the (GCSF) $2 L \alpha$ molecule is bound to the Bk7-glass/Cr-Au/MUA/Protein-G/GCSF-R slide via both GCSF subunits and a complex $(\mathrm{GCSF}-\mathrm{R})_{2}=(\mathrm{GCSF})_{2} L \alpha$ is formed, which is based on two GCSF-Receptors and one (GCSF) ${ }_{2} L \alpha$ molecule, in this case a fraction $\left(\rho_{1}\right)$ of the '(GCSF) $2 L \alpha$ coverage areas', which are theoretically available for binding with (GCSF) $2 L \alpha$, is involved in the formation of (GCSF$R)_{2}=(\text { GCSF })_{2} L \alpha$ complexes. In Stage 3 an irreversibly bounded (GCSF) $2 L \alpha$ is represented, which is involved into a non-dissociable (GCSF-R $)_{2} /(\mathrm{GCSF})_{2} L \alpha$ complex structure that isformed after the rearrangement of the (GCSF-R $)_{2}=(\mathrm{GCSF})_{2} L \alpha$ complex ' 0 '. An unbound (free) (GCSF) ${ }_{2} L \alpha$ molecule binds to one receptor and enters Stage 1 with a rate, which depends on the second

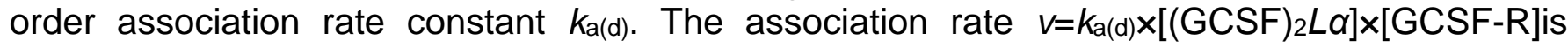
dependent on: (i) $k_{\mathrm{a}}$ (d), (ii) the concentration of (GCSF) ${ }_{2} L \alpha$ in solution $C_{0}$, which was considered to be constant during here described experiments, and (iii) the surface concentration of GCSFReceptor. The dissociation rate consonant $k_{-1}$ characterizes the dissociation of (GCSF-R)$(\mathrm{GCSF})_{2} L \alpha$ and $k-2$ the dissociation of $(\mathrm{GCSF}-\mathrm{R})_{2}=(\mathrm{GCSF})_{2} L \alpha$ complexes. We assumed that both these constants are irelated by $k_{-2}=2 k_{-1}$ because in Stage 2 one (GCSF) $2 L \alpha$ molecule is bonded 
Z. Balevicius, J. Talbot, L. Tamosaitis, I. Plikusiene, A. Stirke, G. Mickiene, S. Balevicius, A. Paulauskas, A. Ramanavicius. Modelling of immunosensor response: the evaluation of binding kinetics between an immobilized receptor and structurally-different genetically engineered ligands. Sensors and Actuators B Chemical 2019, 297, 126770. DOI:10.1016/j.snb.2019.126770

\section{Journal version is available:}

https://www.sciencedirect.com/science/article/abs/pii/S0925400519309700?via\%3Dihub

to two immobilized GCSF-Receptors and the probability that one of those (GCSF) 2 L $\alpha$ binding sites will dissociate from GCSF-Receptor is two times higher in comparison to that, which is observed in the case of (GCSF-R)-(GCSF) 2 L $\alpha$ complex where (GCSF) ${ }_{2} L \alpha$ is bonded via one binding site to a single GCSF-Receptor. Therefore, the same constant is applied for the description of the dissociation of both complexes because both GCSF ligands in (GCSF) $2 L \alpha$ are similar. The interaction rate constant $k_{2}$ characterizes the rate of formation of the (GCSF-R)(GCSF) $2 L \alpha$ complex with a second GCSF-Receptor of already bounded to one GCSF-Receptor via first ligand-site of (GCSF) $)_{2} L \alpha$ what leads to the formation of $(\mathrm{GCSF}-\mathrm{R})_{2}=(\mathrm{GCSF})_{2} L \alpha$ complex. The rate constant $k_{3}$ characterizes the transformation of dissociable (GCSF-R) ${ }_{2}=(\mathrm{GCSF})_{2} L \alpha$ complex into non-dissociable (GCSF-R) $2 /(\text { GCSF })_{2} L \alpha$ complex. Most of the immobilized GCSFReceptors enter this terminal (GCSF-R)2//(GCSF) $2 L \alpha$ complex (Stage 3). 
Z. Balevicius, J. Talbot, L. Tamosaitis, I. Plikusiene, A. Stirke, G. Mickiene, S. Balevicius, A. Paulauskas, A. Ramanavicius. Modelling of immunosensor response: the evaluation of binding kinetics between an immobilized receptor and structurally-different genetically engineered ligands. Sensors and Actuators B Chemical 2019, 297, 126770. DOI:10.1016/j.snb.2019.126770

https://doi.org/10.1016/j.snb.2019.126770

Journal version is available:

https://www.sciencedirect.com/science/article/abs/pii/S0925400519309700?via\%3Dihub

This kinetic model is described by the following system of differential equations:

$\frac{d \rho_{1}}{d t}=k_{1}\left(1-\rho_{1}-\rho_{2}-\rho_{3}\right)-\left(k_{-1}+k_{2}\right) \rho_{1}+k_{-2} \rho_{2}$

$\frac{d \rho_{2}}{d t}=k_{2} \rho_{1}-\left(k_{-2}+k_{3}\right) \rho_{2}$

$\frac{d \rho_{3}}{d t}=k_{3} \rho_{2}$

$k_{-2}=2 k_{-1}$

where $\rho_{1}$ is a fraction of '(GCSF) $2 L \alpha$ coverage areas' ('coverage areas') to which (GCSF) $2 L \alpha$ is bounded via one ligand during the formation of complex (GCSF-R)-(GCSF) $2 L \alpha$ (Stage 1); $\rho_{2}$ is a fraction of 'coverage areas' to which (GCSF) $2 L \alpha$ is bounded via two ligands during the formation of complex (GCSF-R $)_{2}=(\mathrm{GCSF})_{2} L \alpha$ (Stage 2); where $\rho_{3}$ is a fraction of 'coverage areas' to which (GCSF) ${ }_{2} L \alpha$ is bounded via one ligand during the formation of complex (GCSF-R) $2 / /(\mathrm{GCSF})_{2} L \alpha$ (Stage 3). It is important to note that a total number of 'coverage areas' available for the $(\mathrm{GCSF})_{2} L \alpha$ is equal to the maximal number of (GCSF) $2 L \alpha$ molecules, which can bind to Bk7glass/Cr-Au/MUA/Protein-G/GCSF-R slide surface via both GCSF ligands; and in here applied calculations one 'coverage area' is considered as an area on Bk7-glass/Cr-Au/MUA/ProteinG/GCSF-R slide capable to host (GCSF) ${ }_{2} L \alpha$ molecule and bind it via both (GCSF) $2 L \alpha$ ligands. Initial boundary conditions, which were applied for numerical calculations were $\rho_{1}(0)=\rho_{2}(0)=$ $\rho_{3}(0)=0$.

In this case, $1-\rho_{1}-\rho_{2}-\rho_{3}$, is the fraction of 'coverage areas' available for (GCSF) $)_{2} L \alpha$ binding, which provides the probability that (GCSF) 2 L $\alpha$ molecule will find not 'covered areas' on surface of Bk7-glass/Cr-Au/MUA/Protein-G/GCSF-R slide. Taking into account that the Bk7-glass/CrAu/MUA/Protein-G/GCSF-R slide during the incubation in the solution containing (GCSF) $2 \alpha \alpha$ is already partly covered by the other (GCSF) $2 L a$ molecules, $\rho_{1}$ and $\rho_{2}$ are the fractions of 'coverage areas' occupied by (GCSF-R)-(GCSF) ${ }_{2} L \alpha$ and (GCSF-R $)_{2}=(\mathrm{GCSF})_{2} L \alpha$ complexes, respectively and $\rho_{3}$ is the fraction of 'coverage areas' irreversibly occupied by non-dissociable (GCSF$\mathrm{R})_{2} / /(\mathrm{GCSF})_{2} L \alpha$ complexes.

The system based on equations 4-7 has no trivial analytical solution, but can be solved numerically. The results of (GCSF) $2 L \alpha$ association kinetics fitting based on numerical calculation using the system of equations 4-7 is presented in figure 3 (blue curve (2)). Good agreement between experimental data and the model was achieved using the following rate constants $k_{a(d)}$ $=4 \times 10^{5} \mathrm{M}^{-1} \mathrm{~s}^{-1}, k_{2}=142.27 \mathrm{~s}^{-1}, k_{-1}=1.35436 \mathrm{~s}^{-1}, k_{3}=0.0495656 \mathrm{~s}^{-1}$.

The differences among the association rate constants $\left(k_{\mathrm{a}}\right)$ calculated for the interaction of GCSF-Receptors with different GCSF-containing ligand molecules (m GCSF; (GCSF) 2 L $\alpha$ and SCF-L $\alpha$-GCSF) can be explained in the following way: interaction between an immobilized GCSFReceptor and a ligand can only occur only if binding sites of the receptor and the ligand coincide 
Z. Balevicius, J. Talbot, L. Tamosaitis, I. Plikusiene, A. Stirke, G. Mickiene, S. Balevicius, A. Paulauskas, A. Ramanavicius. Modelling of immunosensor response: the evaluation of binding kinetics between an immobilized receptor and structurally-different genetically engineered ligands. Sensors and Actuators B Chemical 2019, 297, 126770. DOI:10.1016/j.snb.2019.126770

https://doi.org/10.1016/j.snb.2019.126770

Journal version is available:

https://www.sciencedirect.com/science/article/abs/pii/S0925400519309700?via\%3Dihub

in space. The receptor's mobility is very limited due to immobilization on the surface of the slide in comparison to that of the ligand. Therefore, the probability of receptor-ligand binding mainly depends on the dynamics of the ligand. Therefore, the association constant can be evaluated using the well-known Barzykin and Shushin equation [29]:

$k_{\mathrm{a}}=K_{\mathrm{s}} f$

where $K_{\mathrm{s}}=4 \pi R \cdot D$ is Smoluchowski rate constant, $R$ is the reactivity radius, $D$ is the diffusion coefficient and $f$ is the steric factor, which for non-spherical molecules depends on both translational and rotational diffusion coefficients. We assume that in our case $R$ is the same not only for GCSF-based subunit in mGCSF and SCF-L $\alpha$-GCSF, but also for (GCSF) $2 L \alpha$ due to the large distance (about 3 diameters of GCSF) between single GCSF units in the (GCSF) 2 L $\alpha$ dimer. This allows to evaluate the ratio between association constants of monomeric mGCSF $(k a(m))$ and dimeric $(\mathrm{GCSF})_{2} L \alpha\left(k_{\mathrm{a}(\mathrm{d})}\right) k_{\mathrm{a}}(\mathrm{m}) / k_{\mathrm{a}(\mathrm{d})}=\left(D_{\mathrm{m}} \times f_{\mathrm{m}}\right) /\left(D_{\mathrm{d}} \times f_{\mathrm{d}}\right)$, where $D_{\mathrm{m}}, D_{\mathrm{d}}, f_{\mathrm{d}}$ and $f_{\mathrm{m}}$ are diffusion coefficients and steric factors of mGCSF and (GCSF) $)_{2} \alpha$ molecules, respectively. The ratio $D_{\mathrm{m}} / D_{\mathrm{d}}$ can be calculated using the Zimm model [30] that relates the diffusion coefficient $(D)$ to the length $(L)$ of molecule, $D \sim L^{-3 / 5}$. Thus $D_{\mathrm{m}} / D_{\mathrm{d}}=\left(L_{\mathrm{m}} / L_{\mathrm{d}}\right)^{-3 / 5}=1.7190$, because the diameters of the monomer and dimer molecules are $L_{\mathrm{m}} \approx 4.86 \mathrm{~nm}$ and $L_{\mathrm{d}} \approx 11,8 \mathrm{~nm}$, respectively (See: http://pdb.org/pdb/explore/explore.do?structureld=2D9Q). Analysis of the kinetics presented in figures 1 and 3 showed that the ratio $k_{a(m)} / k_{a(d)}=1.8660$. This demonstrates that the decrease of the $(\mathrm{GCSF})_{2} L \alpha$ association rate in comparison to that of mGCSF can be explained mainly by the decrease of (GCSF) 2 L $\alpha$ diffusion coefficient, while small changes (about $8 \%$ ) of the steric factor $f$ are not very important for the diffusion. The comparison of association rate constants $\left(k_{a}(\mathrm{~m}) / k_{a}\left(h_{d}\right)\right)$ of monomeric mGCSF $\left(k_{a}(\mathrm{~m})\right)$ and SCF-L $\alpha$-GCSF $\left(k_{a}\left(h_{d}\right)\right)$, which were calculated using the same method, demonstrating that in this case the steric factor of SCF-L $\alpha$-GCSF molecules is 4.7 times lower than that of mGCSF, resulting in a significant decrease of the SCF-L $\alpha$-GCSF association rate with immobilized GCSF-Receptor. This is a result of anisotropic structure and reactivity of SCF-L $\alpha$-GCSF molecules. According to assumption proposed by McCammon [31] anisotropy slows the association rate with respect to that for isotropic molecules of the same size. However, it should be taken into account that the reduction of the association between receptor and ligand cannot be accounted for only on the basis of simple geometrical arguments.

The analysis of mGCSF and SCF-L $\alpha$-GCSF interaction with immobilized GCSF-Receptor kinetics, which are presented in figures 1 and 2, shows that the residence times of GCSF$\mathrm{R} / \mathrm{mGCSF}$ and GCSF-R/SCF-L $\alpha$-GCSF complexes are different. It is reasonable to assume that the strength of receptor-ligand interaction is the same in both the GCSF-R/mGCSF and GCSFR/SCF-La-GCSF complexes and the breaking of this bond occurs when the bound mGCSF or SCF- $L \alpha$-GCSF molecule gains a critical energy due to thermally induced Brownian motions, which is sufficient for the dissociation of GCSF-R/mGCSF and GCSF-R/SCF-L $\alpha$-GCSF complex, respectively. Thus, an increase of molecular mass (by 2.23 times for SCF-La-GCSF in comparison to that of mGCSF) decreases the probability of accelerating the ligand up to such velocities at which the receptor-ligand complex can dissociate. The experimental results show that this probability decreases by a factor of 8 for complex GCSF-R/SCF-L $\alpha$-GCSF in comparison to that of GCSF-R/mGCSF. 
Z. Balevicius, J. Talbot, L. Tamosaitis, I. Plikusiene, A. Stirke, G. Mickiene, S. Balevicius, A. Paulauskas, A. Ramanavicius. Modelling of immunosensor response: the evaluation of binding kinetics between an immobilized receptor and structurally-different genetically engineered ligands. Sensors and Actuators B Chemical 2019, 297, 126770. DOI:10.1016/j.snb.2019.126770

https://doi.org/10.1016/j.snb.2019.126770

Journal version is available:

https://www.sciencedirect.com/science/article/abs/pii/S0925400519309700?via\%3Dihub

In the case of (GCSF-R $)_{2} /(\mathrm{GCSF})_{2} L \alpha$ complex formation, residence times of (GCSF-R)$(\mathrm{GCSF})_{2} L \alpha$ and $(\mathrm{GCSF}-\mathrm{R})_{2}=(\mathrm{GCSF})_{2} L \alpha$ complexes are $0.007 \mathrm{~s}$ and $0.364 \mathrm{~s}$, respectively. This effect is the result of the complex interaction between the (GCSF) $2 L \alpha$ molecule and two immobilized GCSF-receptors. Thus, in this case, the residence time effect manifests mainly through the time during which the (GCSF) 2 L $\alpha$ molecule is involved in (GCSF-R)-(GCSF) ${ }_{2} L \alpha$ and $(\mathrm{GCSF}-\mathrm{R})_{2}=(\mathrm{GCSF})_{2} L \alpha$ complexes (Eq. 3, Stage 1 and Stage 2$)$. The relatively short residence times of both (GCSF-R)-(GCSF) $2 L \alpha$ and $(\mathrm{GCSF}-\mathrm{R})_{2}=(\mathrm{GCSF})_{2} L \alpha$ complexes reveals relatively fast formation of the non-dissociable (GCSF-R) $2 /(\mathrm{GCSF})_{2} L \alpha$ complex and, therefore, the rapid development of TIRE-based analytical signal, which is clearly observed in figure 3 .

\section{CONCLUSIONS, OUTLOOK AND FUTURE TRENDS}

We have demonstrated that an increase of the mass of GCSF-based molecules by the 'fusion' of two GCSF molecules (in the case of (GCSF) $2 L \alpha$ ) or 'fusion' of GCSF molecule with SCF molecule (in the case of SCF-L $\alpha$-GCSF) significantly changes the formation and dissociation characteristics of complexes between these molecules and immobilized GCSF-Receptors. In the formation of $(\text { GCSF-R })_{2} /(G C S F)_{2} L \alpha$ and GCSF-R/SCF-L $\alpha$-GCSF complexes, an increase of the residence times was observed. At fixed the same ligand concentration, residence time increased two times for the GCSF-R/SCF-L $\alpha$-GCSF complex and about 17 times for (GCSF-R) $2 /($ GCSF) 2 L $\alpha$ complex in comparison to the GCSF-R/mGCSF complex, respectively. For (GCSF-R) $)_{2} /(\mathrm{GCSF})_{2} L \alpha$ complex this increase is the result of the decrease of the diffusion coefficient, while in the case of SCF-L $\alpha$-GCSF molecules it is related to a decrease ( 4.7 times) of the steric factor. Doubling the mass of SCF- $L \alpha$-GCSF and (GCSF) ${ }_{2} L \alpha$ molecules in comparison to mGCSF molecules also influences the residence time. It increases about 8 times for GCSF-R/SCF-L $\alpha$-GCSF complexes based on asymmetric SCF-La-GCSF molecules, which have only one interaction site capable of binding to a GCSF-Receptor. In the case of symmetric (GCSF) $2 L \alpha$ molecules, which have two interaction sites capable of binding with GCSF-Receptors, irreversible bonding to the GCSFReceptor was observed. The formation of the (GCSF) $)_{2} L \alpha$ complex with immobilized GCSFReceptor kinetics can be well described by a three-step model in which the last step leads to the formation of a stable (GCSF-R) $2 /(\mathrm{GCSF})_{2} L \alpha$ complex. Finally, we note that (GCSF) $2 L \alpha$ molecules having a larger mass (about 2.2 times in comparison to mGCSF) associate with immobilized GCSF-Receptor only 1.866 times slower, but exhibit a very similar steric factor to that of the SCF$L \alpha$-GCSF and after several reversible association stages it binds irreversibly to a GCSF-Receptor. This makes the (GCSF) $2 L \alpha$ molecule a promising candidate, which is well suitable for significant improvement of GCSF-based drugs.

The present study has demonstrated the applicability of TIRE method based immunosensor together with a newly developed mathematical model that describes the multistep kinetic binding between an immobilized receptor and a dissolved ligand. This approach allows us not only to evaluate receptor-ligand association and dissociation constants, but also provides some information about conformational changes, which have a direct influence on the drug-target residence time and on the pharmacokinetic characteristics. 
Z. Balevicius, J. Talbot, L. Tamosaitis, I. Plikusiene, A. Stirke, G. Mickiene, S. Balevicius, A. Paulauskas, A. Ramanavicius. Modelling of immunosensor response: the evaluation of binding kinetics between an immobilized receptor and structurally-different genetically engineered ligands. Sensors and Actuators B Chemical 2019, 297, 126770. DOI:10.1016/j.snb.2019.126770

https://doi.org/10.1016/j.snb.2019.126770

\section{Journal version is available:}

https://www.sciencedirect.com/science/article/abs/pii/S0925400519309700?via\%3Dihub

More generally, we have proposed a mathematical model that is useful for the modelling of such immunosensor responses in which two interaction sites based proteins (e.g. antibodies) are applied as immobilized receptors or are monitored as analytes (in recent research such two interaction sites based analyte was (GCSF) $\left.{ }_{2} L \alpha\right)$.

Further investigations are need to prove the universality of the kinetic model, which is based on three protein association stages, developed here. Therefore, in ongoing work, we are applying the same mathematical model to evaluate the interaction between the immobilized GCSF-receptor with very different, genetically-engineered, ligands based on GCSF-subunits connected by linkers of different characteristics. This ongoing research is in progress and will be soon reported elsewhere.

\section{ACKNOWLEDGEMENTS}

This research was funded by the European Social Fund under the Global Grant measure "Enzymes functionalized by polymers and biorecognition unit for selective treatment of target cells" (NanoZim's, project No. VP1-3.1-SMM-07-K-02-042).

\section{REFERENCES}

1. Ramanavicius, A., Oztekin, Y., Ramanaviciene, A., 2014. Electrochemical Formation of Polypyrrolebased Layer for Immunosensor Design. Sens. Actuat. B 197, 237-243.

2. Toma K., Miki D., Kishikawa Ch., Yoshimura N., Miyajima K., Arakawa T., Yatsuda H. Mitsubayashi K., 2015. Repetitive Immunoassay with a Surface Acoustic Wave Device and a Highly Stable Protein Monolayer for On-Site Monitoring of AirborneDust Mite Allergens, Anal.Chem., 87, 10470-10474.

3. Ren X., Yan J., Wu D., Wei Q., Wan Y., 2017. Nanobody-Based Apolipoprotein E Immunosensor for Point-of-Care Testing, ACS Sens., 2, 1267-1271.

4. Kidakovaa A., Reuta J., Rappichb J., Öpika A., Syritski V., 2018. Reactive and Functional Preparation of a surface-grafted protein-selective polymerfilm by combineduse of controlled/living radical photopolymerization and microcontactimprinting , Reactive and Functional Polymers 125, 47-56

5. Zhang T., Xing B., Han Q., Lei Y., Dan Wu D., Ren X., Wei Q., 2018. Electrochemical immunosensor for ochratoxin A detection based on Au octahedron plasmonic colloidosomes, Anal. Chim. Acta 1032, $114-121$

6. Ren X., Zhang T., Wu D., Yan T., Pang X, Du B., Lou W., Wei Q., 2017. Increased electrocatalyzed performance through high content potassium doped graphene matrix and aptamer tri infinite amplification labelsstrategy: Highly sensitive for matrix metalloproteinases-2 detection, Bios. and Bioel. 94, 694-700.

7. Zhang T., Ma N., Ali A., Wei Q., Wu D., Ren X., 2018. Electrochemical ultrasensitive detection of cardiac troponin I using covalent organic frameworks for signal amplification, Bios. and Bioel.119, $176-181$. 
Z. Balevicius, J. Talbot, L. Tamosaitis, I. Plikusiene, A. Stirke, G. Mickiene, S. Balevicius, A. Paulauskas, A. Ramanavicius. Modelling of immunosensor response: the evaluation of binding kinetics between an immobilized receptor and structurally-different genetically engineered ligands. Sensors and Actuators B Chemical 2019, 297, 126770. DOI:10.1016/j.snb.2019.126770 https://doi.org/10.1016/j.snb.2019.126770

\section{Journal version is available:}

https://www.sciencedirect.com/science/article/abs/pii/S0925400519309700?via\%3Dihub

8. Ren X., Ma H., Zhang T., Zhang Y., Yan T., Du B., Wei Q., 2017. Sulfur-Doped Graphene-Based Immunological Biosensing Platform for Multianalysis of Cancer Biomarkers, ACS Appl. Mater. Interfaces 9, 37637-37644.

9. X., Lu P., R., Zhang T., Zhang Y., Wu D., Wei Q., 2018. An ITO-based point-of-care colorimetric immunosensor for ochratoxin A detection, Talanta 188, 593-599

10. Bari S. M. I., Reis L.G., Nestorova G. G., 2019. Calorimetric sandwich-type immunosensor for quantification of TNF- $\alpha$, Bios. and Bioel.126, 82-87.

11. Aleksei Tretjakov A., Vitali Syritski V., Jekaterina Reut J., Roman Boroznjak R., Andres Öpik A., 2016. Molecularly imprinted polymer film interfaced with Surface AcousticWave technology as a sensing platform for label-free protein detection, Anal. Chim. Acta 902, 182-188.

12. Toma K., Miki D., Kishikawa C., Yoshimura N., Miyajima K., Arakawa T., Yatsuda H., Mitsubayashi K., 2015. Repetitive Immunoassay with a Surface Acoustic Wave Device and aHighly Stable Protein Monolayer for On-Site Monitoring of AirborneDust Mite Allergens, Anal.Chem. 87, 10470-10474.

13. Tretjakov A., Syritski V., Reut J., Boroznjak R., Volobujeva O., Öpik A., 2013. Surface molecularly imprinted polydopamine filmsfor recognition of immunoglobulin G, Microchim. Acta 180, 1433-1442.

14. Maglio O., Costanzo S., Cercola R., Zambrano G., Mauro M., Battaglia R., Ferrini G., Nastri F., Pavone V, Lombardi A., 2017. A Quartz Crystal Microbalance Immunosensor for Stem Cell Selection and Extraction, Sensors 12, 27-47.

15. Copeland, R.A., Pompliano, D.L., Meek, T.D., 2006. Drug-target residence time and its implications for lead optimization. Nat. Rev. Drug Discov. 5, 730-739.

16. Copeland, R.A., 2016. The drug-target residence time model: a 10-year retrospective. Nat. Rev. Drug Discov. 15, 87-95.

17. Tummino, P.J., Copeland, R.A., 2008. Residence Time of Receptor-Ligand Complexes and Its Effect on Biological Function. Biochemistry 47, 5481-5492.

18. Balevicius, Z., Baleviciute, I., Tumenas, S., Tamosaitis, L., Stirke, A., Makaraviciute, A., Ramanaviciene, A., Ramanavicius, A., 2014. In situ study of ligand-receptor interaction by total internal reflection ellipsometry. Thin Solid Films 571, 744-748.

19. Sanchez-Ramos, J., Song, S., Sava, V., Catlow, B., Lin, X., Mori, T., Cao, C., Arendash, G.W., 2009. Granulocyte colony stimulating factor decreases brain amyloid burden and reverses cognitive impairment in Alzheimer's mice. Neuroscience 163, 55-72.

20. Mickiene, G., Dalgediene, I., Dapkunas, Z., Zvirblis, G., Pesliakas, H., Kaupinis, A., Valius, M., Mistiniene, E., Pleckaityte, M., 2017. Construction, Purification, and Characterization of a Homodimeric Granulocyte Colony-Stimulating Factor. Mol. Biotechnol. 59, 374-384.

21. Pesliakas J.H., Pleckaityte M, Mistiniene E., Zvirblyte G., Petreikyte I., Leiva A., Stirke A., Z.G., 2015. Fused proteins of granulocyte colony-stimulating factor with other partners of growth factor, preferably with stem cell factor, and method of preparation thereof. WO2015047062A1.

22. Danielson, U.H., 2009. Integrating surface plasmon resonance biosensor-based interaction kinetic analyses into the lead discovery and optimization process. Future Med. Chem. 1, 1399-1414.

23. Poksinski, M., Arwin, H., 2007. Total internal reflection ellipsometry: ultrahigh sensitivity for protein adsorption on metal surfaces. Opt. Lett. 32, 1308. 
Z. Balevicius, J. Talbot, L. Tamosaitis, I. Plikusiene, A. Stirke, G. Mickiene, S. Balevicius, A. Paulauskas, A. Ramanavicius. Modelling of immunosensor response: the evaluation of binding kinetics between an immobilized receptor and structurally-different genetically engineered ligands. Sensors and Actuators B Chemical 2019, 297,

\section{Journal version is available:}

https://www.sciencedirect.com/science/article/abs/pii/S0925400519309700?via\%3Dihub

24. Balevicius, Z., Makaraviciute, A., Babonas, G.-J., Tumenas, S., Bukauskas, V., Ramanaviciene, A., Ramanavicius, A., 2013. Study of optical anisotropy in thin molecular layers by total internal reflection ellipsometry. Sensors Actuators B Chem. 181, 119-124.

25. Balevicius, Z., Paulauskas, A., Plikusiene, I., Mikoliunaite, L., Bechelany, M., Popov, A., Ramanavicius, A., Ramanaviciene, A., 2018. Towards the application of Al 2 O 3 /ZnO nanolaminates in immunosensors: total internal reflection spectroscopic ellipsometry based evaluation of BSA immobilization. J. Mater. Chem. C 6, 8778-8783.

26. Andrade, J.D., Hlady, V., 1986. Protein adsorption and materials biocompatibility: A tutorial review and suggested hypotheses, in: Biopolymers/Non-Exclusion HPLC. Advances in Polymer Science, Vol 79. Springer, Berlin, Heidelberg. pp. 1-63.

27. Van Tassel, P.R., Guemouri, L., Ramsden, J.J., Tarjus, G., Viot, P., Talbot, J., 1998. A Particle-Level Model of Irreversible Protein Adsorption with a Postadsorption Transition. J. Colloid Interface Sci. 207, 317-323.

28. Wahlgren, M., 1991. Protein adsorption to solid surfaces. Trends Biotechnol. 9, 201-208.

29. Barzykin, A.V., Shushin, A.I., 2001. Effect of Anisotropic Reactivity on the Rate of DiffusionControlled Reactions: Comparative Analysis of the Models of Patches and Hemispheres. Biophys. J. 80, 2062-2073.

30. Edwards, M.D. and S.F., 1988. The Theory of Polymer Dynamics. Clarendon Press, Oxford.

31. McCammon, J.A., 1984. Protein dynamics. Reports Prog. Phys. 47, 1-46. 
Z. Balevicius, J. Talbot, L. Tamosaitis, I. Plikusiene, A. Stirke, G. Mickiene, S. Balevicius, A. Paulauskas, A. Ramanavicius. Modelling of immunosensor response: the evaluation of binding kinetics between an immobilized receptor and structurally-different genetically engineered ligands. Sensors and Actuators B Chemical 2019, 297, 126770. DOI:10.1016/j.snb.2019.126770

\section{Journal version is available:}

https://www.sciencedirect.com/science/article/abs/pii/S0925400519309700?via\%3Dihub

\section{Graphical Abstract}

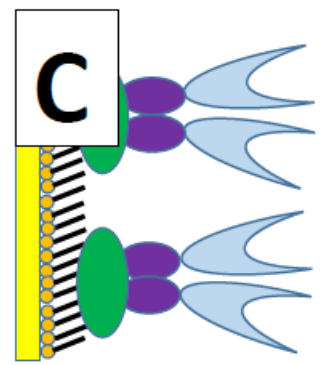

Stage 0
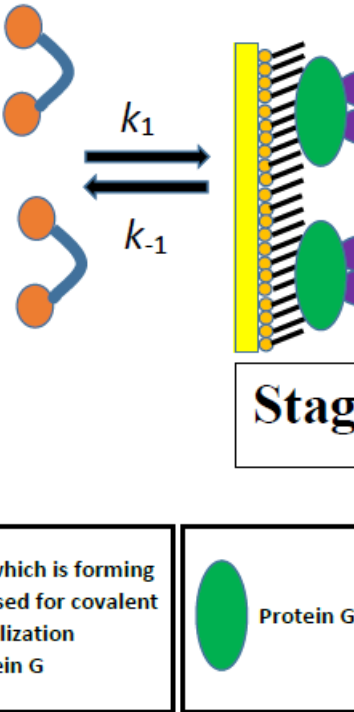

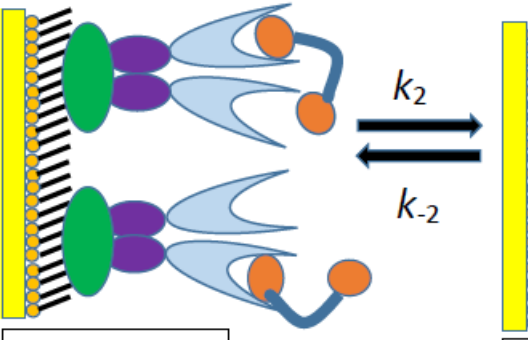

Stage 2

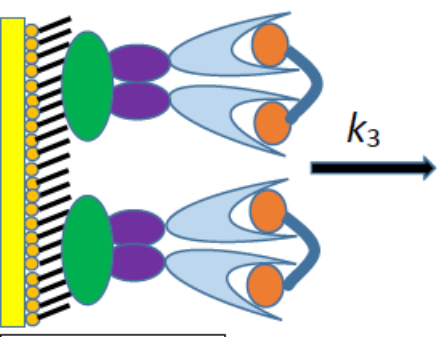

Stage 3

Au-layer $\begin{aligned} & \text { MUA, which is forming } \\ & \text { SAM, used for covalent } \\ & \text { immobilization } \\ & \text { of Protein } \mathrm{G}\end{aligned}$

